\title{
TRANSIÇÕES EM DIREÇÃO AO USO SUSTENTÁVEL E CONSERVAÇÃOO DOS CAMPOS SULINOS GAÚCHOS: O LUGAR DA PECUÁRIA FAMILIAR
}

\author{
Marcelo Porto Nicola ${ }^{1}$ \\ Flávia Charão Marques ${ }^{2}$
}

\begin{abstract}
RESUMO
O artigo se refere às dinâmicas sociotécnicas na pecuária familiar gaúcha realçando a relevância das experiências de desenvolvimento rural em comunidades de pecuaristas familiares no Rio Grande do Sul. Ele também salienta a necessidade de aprofundamento das pesquisas e estímulo às políticas públicas que valorizam a transição da agricultura em direção à conservação e uso sustentável das ameaçadas áreas campestres do Estado. O cultivo de grãos, a silvicultura e o manejo inadequado dos campos estão entre as principais causas da degradação, que já suprimiram mais da metade da área original desses recursos nativos, cuja multifuncionalidade vai muito além da tradicional e conhecida produção de proteína animal. Para a melhor compreensão da gestão desse premente processo transicional o trabalho apresenta a Perspectiva Multinível enquanto abordagem potencialmente capaz para investigar os elementos que explicam como múltiplos atores locais e regionais articulam trajetórias e repertórios originais de desenvolvimento rural, trazendo aportes importantes para a formulação de políticas. Esse estudo, que se apoia em revisão bibliográfica, atribui e identifica papel central ao pecuarista familiar e seus rebanhos, na medida em que este grupo social está envolvido com processos de coprodução criativos, adaptados e contextualizados localmente.
\end{abstract}

Palavras-chave: agricultura familiar, sustentabilidade, transições sociotécnicas.

\section{TRANSITIONS TOWARDS SUSTAINABLE USE AND CONSERVATION OF GAUCHOS SOUTHERN FIELDS: THE PLACE OF FAMILY CATTLE BREEDING}

\begin{abstract}
The article refers to the socio-technical dynamics in the gaucho family livestock highlighting the importance of rural development experiences in family ranchers communities in Rio Grande do Sul. He also stresses the need for further development of research and encouragement of public policies that value the

\footnotetext{
1 Graduado em Engenharia Agronômica (UFPEL). Mestrado em Extensão Rural (PPG ExR/UFSM). Doutorado em Desenvolvimento Rural (PGDR/UFRGS). Gerente Técnico da Estação Experimental Agronômica/FAGRO/UFRGS. E-mail: mrprnicola@gmail.com.

2 Graduada em Agronomia (UFRGS). Mestrado em Fitotecnia (PPG Fitotecnia/UFRGS). Doutorado em Desenvolvimento Rural (PGDR/UFRGS). Professora Adjunta do Curso de Agronomia e do Programa de Pós
} Graduação em Desenvolvimento Rural (UFRGS). E-mail: flavia.marques@ufrgs.br.
\end{abstract}


transition from agriculture towards the conservation and sustainable use of threatened countryside in the State. The grain crops, forestry and inadequate management of the fields are among the main causes of degradation, which have already removed more than half of the original area of these native resources, the multifunctionality goes far beyond the traditional and known production of animal protein. For better understanding of the management of urgent transitional work process presents the Multilevel Perspective approach while potentially able to investigate the factors that explain how multiple local and regional actors articulate original trajectories and repertoires of rural development, bringing important contributions to the formulation of policies. This study, which is based on literature review, attributes and identifies key role to family ranchers and their cattle, to the extent that this social group is involved with creative co-production processes, adapted and contextualized locally.

Keywords: family farming, socio-technical transition, sustainability.

\section{INTRODUÇÃO}

Este artigo se propõe, partindo de revisão bibliográfica, a abordar as especificidades e potencialidades da pecuária familiar em associação com múltiplos atores locais e regionais para levarem adiante dinâmicas sociotécnicas que estimulam movimentos de transição em direção ao uso sustentável e conservação das áreas campestres no Rio Grande do Sul. Essas dinâmicas se desdobram, apesar de estarem embutidas em contextos aparentemente governados por um regime dominante da pecuária, caracterizado por um conjunto de tecnologias enraizadas, cadeias longas de abastecimento, estruturas legais, instituições e percepções prevalentes.

Entende-se, aqui, que o pecuarista familiar, a despeito estar entre os grupos sociais marginalizados no processo da modernização e padronização técnica da agricultura, possui significativas potencialidades relacionadas ao uso sustentável e conservação dos ameaçados campos sulinos. Grupos com estas características são portadores de singularidades culturais, cognitivas e técnicas que podem significar justamente o diferencial para a emergência de inovações contextualizadas localmente e para processos endógenos ${ }^{3}$ de desenvolvimento. Mais especificamente, os pecuaristas familiares estão envolvidos com a coprodução de ovinos, bovinos e derivados, em sistemas de criação adaptados aos contextos locais, em seus aspectos históricos, sociais, técnicos e ambientais. Neste sentido, se está considerando que essas dinâmicas configuram processos diferenciados e originais de desenvolvimento rural que vem emergindo no estado.

O recurso forrageiro nativo, disponível como cobertura vegetal dominante no bioma Pampa e nas áreas campestres do bioma Mata Atlântica do Rio Grande do Sul, tem se constituído num dos principais fundamentos da pecuária de corte explorada por agricultores familiares. Entretanto, esses ecossistemas têm sofrido nas últimas seis décadas uma escalada de agressões que ameaçam a sua existência. Essa intensificação da degradação dos campos está intimamente relacionada com o processo de evolução e consolidação do regime (ou conjunto de regimes) sociotécnico da agricultura modernizada.

\footnotetext{
${ }^{3}$ Endógeno porque busca valorizar, utilizar e exercer controle sobre recursos locais e pelo fato de que os benefícios gerados pelo desenvolvimento são significativamente apreendidos localmente.
} 
O presente trabalho apresenta alguns elementos para pensar o desenvolvimento rural contemporâneo, na tentativa de superar a marcante divisão entre "moderno" e "tradicional". Também, é realçada a abordagem teóricometodológica que tem sido recorrentemente empregada para o estudo das transições ${ }^{4}$. Além de destacar a Perspectiva Multinível como abordagem potencialmente útil para o estudo das transições, pretende-se trazer elementos para compreender melhor como as transições ocorrem na agricultura e como são geradas novidades nos processos de desenvolvimento rural.

Deste modo, são dois os aspectos que auxiliam a problematizar a necessidade de 'facilitar' processos de transição para a sustentabilidade no desenvolvimento. O primeiro se refere à problemática da degradação do bioma Pampa, documentada em um número significativo de pesquisas específicas ${ }^{5}$. Sendo a ascensão da categoria social dos pecuaristas familiares o segundo aspecto a ser abordado. De certa maneira, um ponto referencial entre a pecuária familiar e a degradação do bioma é o crescimento e intensificação de uma agricultura modernizada convencional. Assim, na sequência, o texto trará um esboço do regime sociotécnico ${ }^{6}$ prevalente da pecuária de corte que consolidou tipos específicos de produtor em determinadas regiões. A partir disto, pretende-se demonstrar que parcela significativa de pecuaristas, ao contrário, pratica uma exploração pecuária que se inseriu parcialmente ou não se inseriu nesta lógica dominante. Esta reflexão sobre as heterogeneidades emergentes que acabam por gerar 'contra movimentos' em relação ao processo desenvolvimentista, finalmente, conduz o debate sobre o papel central da pecuária e dos pecuaristas familiares para o desenvolvimento sustentável das áreas campestres do Rio Grande do Sul.

\section{O BIOMA PAMPA E SEUS ATORES, OS PECUARISTAS FAMILIARES}

Os campos sulinos, de acordo Pillar et al (2009), estão presentes nos biomas brasileiros, Pampa e Mata Atlântica, ocupando áreas significativas do Rio Grande do Sul (RS), mas também áreas nos estados de Santa Catarina e Paraná, além de amplas regiões do Uruguai e Argentina. Especificamente, o Bioma Pampa está localizado na metade sul do RS, ocupando aproximadamente $63 \%$ da superfície do estado (IBGE, 2004). Sua importância se relaciona com a garantia de serviços ambientais fundamentais, como a conservação de recursos hídricos, o aumento da taxa de infiltração da água da chuva, a prevenção da erosão do solo, a disponibilidade de polinizadores, e o provimento de recursos genéticos. Além do mais, têm sido a principal fonte forrageira para a pecuária e oferece beleza cênica com potencial turístico importante (PILLAR et al., 2009).

Soma-se a estes aspectos o fato de que, em 2004, as áreas campestres do RS foram reconhecidas oficialmente como um Bioma Nacional. O reconhecimento pode ser considerado fruto da mobilização de ambientalistas, mas também está relacionado ao reconhecimento da pecuária familiar, e às pesquisas científicas anteriores (e intensificadas nos anos 2000) que buscaram desvendar interações

\footnotetext{
${ }^{4}$ Como será visto adiante, o desenvolvimento rural contemporâneo é compreendido como um movimento transicional (PLOEG et al., 2004; STUIVER et al., 2004; VENTURA; MILONE, 2004; PLOEG, 2008; PLOEG; MARSDEN, 2008).

${ }^{5}$ Para mais detalhes consultar Pillar et al. (2009).

${ }^{6} \mathrm{O}$ trabalho utilizará o termo regime sociotécnico, ao invés de regime tecnológico, por entender que ele dá conta de forma mais abrangente do que acontece no nível de regime e nos processos de transição como um todo. Regimes e transições de regime envolvem muito mais que tecnologia. $\mathrm{O}$ termo sociotécnico abrange à existência de um incrustamento de aspectos econômicos e tecnológicos em contextos sociológicos (mais detalhes adiante).
} 
biológicas complexas em um espaço geográfico de alta diversidade, cujo histórico de ocupação, ainda no século XVI, esteve altamente correlacionado à introdução do gado bovino. Recorrentemente, resultados de pesquisa têm indicado o pecuarista familiar como um ator social imprescindível para a conservação e uso sustentável dos campos gaúchos, capaz de conferir ao processo de desenvolvimento nas comunidades e regiões, maior equilíbrio entre as dimensões ambiental, social e econômica. Tendo isto como uma assunção prévia é que são trazidos, em seguida, elementos para refletir sobre a ameaça sobre o bioma, bem como o reconhecimento desses pecuaristas.

\subsection{Os campos sulinos entre ameaças e a potencial conservação}

Carvalho et al. (2006) relatam que são dois os fenômenos mais preocupantes e ameaçadores à existência deste importante recurso natural. Um deles é a expansão da fronteira agrícola, representada especialmente pelos cultivos agrícolas, como a soja, bem como o florestamento (especialmente o eucalipto) e o plantio de pastagens com espécies exóticas. O outro é o sobre pastejo, ocasionado pelo excesso de lotação animal empregado no manejo das pastagens nativas.

Além das ameaças relatadas acima, Nabinger, Carvalho e Dall'agnol (2005), Nabinger e Carvalho (2008) acrescentam o que consideram técnicas equivocadas de "melhoramento" dos campos nativos, mal concebidas e mal executadas, tais como a aplicação abusiva de herbicidas de ação total na implantação de pastagens exóticas. Nesse contexto, no qual diversas ameaças ao recurso forrageiro nativo e práticas de manejo inadequadas podem ser confrontadas pela ação benéfica dos rebanhos herbívoros e seus manejadores, revestem-se de significado os desafios implicados na conservação associada ao uso sustentável dos campos sulinos.

Conforme Valls et al. (2009), estudos realizados em universidades e centros de pesquisa do cone sul $^{7}$ mostram o indiscutível potencial das espécies forrageiras nativas, adaptadas às condições locais há milhares de anos, como componentes dos campos naturais capazes de sustentar integralmente, a base alimentar da exploração pecuária, sem a necessidade de lançar mão de recursos exógenos. Esse potencial forrageiro natural dos campos associado à história de ocupação do território sulino, fortemente vinculada à exploração pecuária, fez com que ao longo de quase quatro séculos, a importância e valorização dos ecossistemas campestres se apoiasse quase exclusivamente em sua capacidade de produzir proteína animal. Somente no final do século $X X$, esse cenário de importância unidimensional do recurso começa, paulatinamente, a se transformar.

No Brasil, a mobilização de setores ambientalistas, governamentais e não governamentais, se desencadeia a partir da preocupação com o futuro da diversidade e conservação dos campos, no bioma Pampa e nos Campos de Cima da Serra (BENCKE, 2009).

Esse quadro gerou a intensificação das diligências investigativas sobre as características e dinâmicas ecológicas dos Campos Sulinos e sua conservação, frente a um quadro alarmante de degradação e extinção de espécies da flora e fauna. Os resultados indicam que a atividade pecuária manejada por princípios sustentáveis de produção, tendo como base alimentar dos rebanhos as pastagens nativas, configura-se como o principal setor produtivo a ser apoiado com vistas à conservação desses biomas. Essa atividade pode ser altamente produtiva, pode

\footnotetext{
${ }^{7}$ Para detalhes sobre locais de pesquisa e obras de referência no cone sul consultar Valls et al. (2009, p. $142,143,147-154)$.
} 
manter a integridade dos ecossistemas campestres e demais serviços ambientais e pode alavancar 0 desenvolvimento das regiões campestres (NABINGER, CARVALHO E DALL'AGNOL, 2005; NABINGER et al., 2009; CARVALHO et al., 2006; et al.,). Nesse caminho, conciliam-se o fortalecimento de um significativo segmento social, os pecuaristas familiares, e a conservação dos ecossistemas campestres, representativos para a cultura, a economia e paisagem gaúcha.

\subsection{Ascensão de uma nova categoria social: o pecuarista familiar}

O interesse renovado pela agricultura familiar, em décadas recentes, fez ressurgir o debate sobre as noções de campesinato e agricultura camponesa como elementos fundamentais para a compreensão das dinâmicas contraditórias que vêm ocorrendo no meio rural, decorrentes de três estilos fundamentais de agricultura: a capitalista, a empresarial e a camponesa (PLOEG, 2008). Como resultado deste debate se consolida a premissa de que a agricultura familiar abrange duas configurações contrastantes, a forma camponesa ${ }^{8}$ e a forma empresarial (PLOEG, 2008).

No Brasil, nos anos 1990, o ressurgimento do debate sobre desenvolvimento rural e a valorização da agricultura familiar (AF) como segmento social estratégico para o desenvolvimento nacional foi estimulado por uma mudança de enfoque e de entendimento desse processo, revitalizando o tema e gerando novas abordagens. Esta retomada foi fortemente influenciada por transformações sociais, políticas e econômicas em diferentes âmbitos do Estado, da sociedade e nos enfoques analíticos dos próprios pesquisadores (SCHNEIDER, 2010). Estas mudanças gerais desdobraram-se em políticas governamentais ${ }^{9}$ direcionadas para a agricultura familiar, para a reforma agrária, territórios rurais, para as mulheres, aposentados, negros e os jovens.

Conforme Wanderley (1996) e Sabourin (2009), a maioria da agricultura familiar brasileira reveste-se de características camponesas, constituindo-se em uma categoria social importante para o país. No interior desse conjunto heterogêneo e importante que constitui a agricultura familiar, ganha visibilidade, no extremo sul brasileiro, a partir dos anos 2000 (RIBEIRO, 2003; 2009), um segmento constituinte dessa diversidade, o pecuarista familiar.

De acordo com o Decreto no 48.316 do Executivo Estadual, são considerados pecuaristas familiares os produtores que atendam simultaneamente às seguintes condições: i - tenham como atividade predominante a cria ou a recria de bovinos e/ou caprinos e/ou bubalinos e/ou ovinos com a finalidade de corte; ii utilizem na produção trabalho predominantemente familiar, podendo utilizar mão de obra contratada em até cento e vinte dias ao ano; iii - detenham a posse, a qualquer título, de estabelecimento rural com área total, contínua ou não, inferior a trezentos hectares; iv - tenham residência no próprio estabelecimento ou em local próximo a ele; e v - obtenham no mínimo setenta por cento da sua renda provinda da atividade pecuária e não agropecuária do estabelecimento, excluídos os benefícios sociais e

\footnotetext{
${ }^{8}$ As pesquisas de campo do Projeto Alto Camaquã identificaram que a exploração pecuária, levada adiante por agricultores familiares da Serra do Sudeste do Rio Grande do Sul, é um tipo de agricultura camponesa, pelas seguintes características que apresenta: baixo grau de mercantilização; alta dependência dos recursos naturais; forma de produção "adaptativa"; resultado de co-evolução socioecológica; produtora de externalidades positivas; e impactos reversíveis sobre o ambiente (BORBA et al., 2009).

${ }_{9}$ As mais emblemáticas são: o PRONAF, lançado pelo governo federal em 1995/96; a universalização da Previdência Social Rural nos anos 1990; e o avanço na execução dos projetos de assentamentos rurais e no crédito fundiário (LEITE, 2009).
} 
os proventos previdenciários decorrentes de atividades rurais (RIO GRANDE DO SUL, 2011).

Trabalhos de prospecção deste segmento social e estimativa da sua representação numérica concluíram que eles abrangem aproximadamente $10 \%$ do total de produtores rurais do Estado, ou seja, cerca de 45.000 famílias (RIBEIRO, 2003). Apesar de apresentarem baixa renda, eles constituem um segmento social que têm importantes contribuições a dar, atuais e futuras, em relação à questão ambiental e aos processos de desenvolvimento rural, entendidos amplamente, além da dimensão estritamente econômica (RIBEIRO, 2003; 2009).

Uma das características mais marcantes da agricultura camponesa é a multifuncionalidade (CARNEIRO, 2002; 2006; PLOEG, 2008). Além disso, a produção é orientada para o mercado, mas também para a reprodução da unidade agrícola e da família. Enquanto os camponeses tentam distanciar suas práticas agrícolas dos mercados 'convencionais', por meio de uma diversidade de mecanismos originais, os agricultores empresariais tornam-se intimamente dependentes dos mercados (principalmente de insumos, mas também de transformação e distribuição). Desta forma, a agricultura camponesa acaba por desenvolver-se como um 'contra movimento' ${ }^{10}$, tendo por característica garantir processos de produção multifuncionais que combinam produtividade com sustentabilidade ambiental e asseguram a reprodução de recursos culturais e naturais (VENTURA; MILONE, 2004).

Esta compreensão é central para apreender o papel dos pecuaristas familiares no desenvolvimento, especialmente, tomando em conta a íntima vinculação com a questão do uso sustentável e conservação dos ecossistemas. Particularmente, no contexto dos campos sulinos, como mencionado acima, é a ascensão dos movimentos de mobilização em defesa do bioma Pampa, que também ajudam a revelar e valorizar o pecuarista familiar e, consequentemente, seu modo 'tradicional' de exploração do meio ${ }^{11}$ como chave para o estabelecimento de processos de conservação. No entanto, a prevalência da relação do 'tradicional' ao atraso e do desenvolvimento como fruto do avanço tecnológico linear ainda precisam ser problematizados no sentido de buscar alguns novos entendimentos. A próxima seção do artigo, justamente, trará um debate teórico recente para pensar o desenvolvimento rural.

\section{DESFAZENDO A DICOTOMIA ENTRE “MODERNO" E "TRADICIONAL"}

Foi-se o tempo em que o desenvolvimento rural (DR) era compreendido hegemonicamente como um caminho único a ser seguido, baseado em avaliações e definições externas com orientação teórica na modernização agrária liberal (GUZMÁN, 2009). Hoje, ganha força a ideia do desenvolvimento rural como um processo heterogêneo, descontínuo, multidimensional, complexo, com muitas faces e negociado localmente. Nesse contexto, a dicotomia (ou um quase maniqueísmo) entre "moderno" e "tradicional" é um exercício sem propósito, apesar de ainda percebido na caracterização, compreensão ou promoção do desenvolvimento rural.

Uma vez que o saber local tem sido valorizado, reconhecendo-se os agricultores como detentores de competências e habilidades, em todas as áreas nas

\footnotetext{
${ }^{10} \mathrm{O}$ 'contra' movimento é constituído pelas novas e alternativas rotas de desenvolvimento e transições tecnológicas em direção a sustentabilidade, as quais enfrentam, geralmente, um ambiente de restrições e dificuldades imposto pelo regime prevalente. Aqui, mais especificamente, se está considerando que o movimento dominante é aquele vinculado a consolidação da agricultura "modernizada" convencional.

${ }_{11}$ Aqui se faz referência, em especial, ao manejo de rebanhos bovino e ovino sobre recursos forrageiros nativos.
} 
quais o desenvolvimento é levado em consideração, fica difícil representar esses conhecimentos como anacrônicos (SARDAN, 2005; DONAZOLLO; BALEM; SILVEIRA, 2012). Por outro lado, em nossa realidade, a unidade de produção familiar opera no interior de um contexto capitalista, cujo arsenal técnicoepistemológico a condiciona e a afeta intensamente, apesar de não governá-la de forma direta (PLOEG, 2013). Assim sendo, o caminho analítico frutífero deve ir além deste divisor entre "moderno" e "tradicional", deve-se considerar a existência simultânea de modernidades múltiplas, aquelas grandes e prevalentes, e as pequenas e alternativas, todas frutos do encontro entre as tradições e as modernidades. De maneira que não há nada fora da modernidade (ESCOBAR, 2002).

\subsection{Notas sobre o desenvolvimento e sua localização}

Diante de um cenário que, ao contrário da homogeneização perseguida pela modernização, contempla diversidades e heterogeneidades importantes, percebe-se o desenvolvimento rural como um processo em desdobramento dinâmico. Ellis e Biggs (2001), estudando a evolução dos temas influentes em desenvolvimento rural, identificaram que durante os anos 1980 e 1990 ocorreu uma importante mudança de paradigma no tratamento do desenvolvimento rural, com um deslocamento a partir da Abordagem Top-down (tecnologias externas e políticas em nível nacional) em direção a Abordagem Bottom-up. Esse movimento deu ênfase à noção de desenvolvimento rural como uma sequência de eventos participativos que favorecem as populações rurais na tomada de controle sobre as suas próprias prioridades de transformação. Ray (1999) enfatiza que a noção de "desenvolvimento endógeno" e a abordagem Bottom-up parecem ter se estabelecido firmemente nos anos 1990; a partir da constatação de que os fazedores de política europeus, no nível estatal e supra-estatal, estavam crescentemente incorporando os termos "bottom-up", "participativo" e "local" a fim de assinalar os novos estilos de intervenção na busca por respostas para os problemas das sociedades rurais. Observando-se a realidade nacional de construção de políticas para os espaços rurais pode-se perceber uma tendência semelhante.

Nos anos 1990, no Brasil, se consolidam as recomendações de valorização do local, da participação e da endogeneidade para um estilo de intervenção para o desenvolvimento que atenda aos preceitos de justiça social, com ações dirigidas a segmentos, até então, pouco visíveis e atendidos pelas políticas públicas; às demandas por sustentabilidade; e aos requisitos de crescimento econômico equitativo (SCHNEIDER, 2010).

De acordo com Ray (1999), o desenvolvimento deveria ser conceitualizado como um processo de animação das capacidades nativas, as quais, uma vez ativadas, conduziriam para uma dinâmica autossustentada. Ploeg (2000) ressalta que é essencial reconhecer o desenvolvimento rural como um processo multinível e multifacetado que emerge como uma série de respostas ao paradigma da modernização. Quando está centrado na agricultura familiar camponesa ${ }^{12}$, implica os seguintes aspectos, tomados isoladamente ou interligados: i - criação de novos produtos e serviços; ii - criação de novos mercados; iii - formas de redução de

\footnotetext{
${ }^{12}$ Pesquisas de campo do Projeto Alto Camaquã identificaram que a exploração pecuária, levada adiante por agricultores familiares da Serra do Sudeste do Rio Grande do Sul, é um tipo de agricultura camponesa, pelas seguintes características que apresenta: baixo grau de mercantilização; alta dependência dos recursos naturais; forma de produção "adaptativa"; resultado de co-evolução socioecológica; produtora de externalidades positivas; e impactos reversíveis sobre o ambiente (BORBA et al., 2009).
} 
custos; iv - aumento do valor dos produtos; e v - a pluriatividade, associada com a transferência de recursos da economia urbana para a rural. Apesar de ser um processo reconhecidamente autodirigido e autônomo, está sendo crescentemente facilitado e fortalecido por políticas públicas nos âmbitos, local, regional, nacional e internacional (PLOEG, 2000).

Ploeg e Marsden (2008) apresentam o desenvolvimento rural como um processo de revitalização do rural, tornando-o mais atrativo, acessível, valioso e útil para a sociedade como um todo. Em seu conjunto multidimensional ${ }^{13}$ representa uma crítica aos pressupostos do paradigma hegemônico, capitalista e modernizador, cujas consequências sociais e ecológicas de aumento da desigualdade e de destruição ambiental não são alentadoras e tem atuado como catalisadores de questionamentos quanto as suas possibilidades de manutenção e evolução futura (PLOEG; MARSDEN, 2008).

Essas maneiras de ver o desenvolvimento rural contemporâneo o configuram como um movimento transicional que se propõe a superar paradigmas estabelecidos. Para analisá-lo, com a complexidade que o tema exige, argumenta-se que é necessário o uso de uma abordagem multinível que focaliza a interação entre tecnologia e sociedade, levando em conta as noções de co-evolução e coprodução $^{14}$, dando atenção aos componentes sócio-institucionais e aos componentes materiais de novidades emergentes e, especificamente, às complexas inter-relações entre os dois (MOORS et al., 2004; GEELS, 2004). O termo novidade designa as melhorias no modo de pensar e fazer, que (re) configuram recursos, atividades, transações e redes locais. Além da dimensão técnico-produtiva, a novidade considera as mudanças cognitivas, sociais, organizacionais e institucionais que podem estar ocorrendo em processos de desenvolvimento rural localizados geograficamente. Para o caso específico deste trabalho, novidade é o termo chave para designar aquela inovação que surge na especificidade única de um dado local dos campos do RS, com forte vinculação e enraizamento ao território e aos repertórios histórico-culturais dos pecuaristas familiares. E como acontece a produção de novidades na agricultura? De acordo com Ploeg et al. (2004) é um processo altamente localizado. É dependente dos ecossistemas locais e dos repertórios culturais, nos quais a organização do processo de trabalho está enraizada. É um processo que emerge e resulta de um entrelaçamento vigoroso com o conhecimento local.

\footnotetext{
${ }^{13}$ A endogeneidade, sustentabilidade, capital social, criação de novidades, governabilidade dos mercados, e os novos arranjos institucionais são as dimensões do DR, a partir das quais se configura o que os autores denominam a "rede rural", com potencial analítico e diferenciador para as economias regionais intensas ou fracas. Quanto mais dimensões do DR estiverem presentes e mais intensamente articuladas na "rede rural" maior será o dinamismo da economia regional em questão. Para mais detalhes sobre as "redes rurais" consultar Ploeg e Marsden (2008) e Ploeg (2011). Mior (2006) apresenta e discute as redes horizontais e verticais e suas relações com o desenvolvimento rural. A noção de redes horizontais aproxima-se da noção de "rede rural", ambas fortemente associadas de maneira subjacente ao DR e ao desenvolvimento territorial. As seis dimensões teóricas das redes rurais ou do desenvolvimento rural estão detalhadamente apresentadas em Ploeg e Marsden (2008, p. 1-28).

${ }^{14} \mathrm{~A}$ interação entre tecnologia e sociedade, ou seja, a interface dinâmica e mútua entre transformação social e técnica, é considerada como um processo de co-evolução e coprodução na qual o contexto social e tecnologia interagem e mudam ao longo do tempo. Um processo co-evolucionário implica que opções tecnológicas, preferências dos usuários, crenças e percepções compartilhadas, e as mudanças institucionais não são dadas de antemão, necessitam ser criadas e configuradas na medida em que o processo de transição avança (MOORS et al., 2004).
} 


\subsection{Perspectiva multinível-pmn para análise das transições}

A transição na agricultura se processa através de mudanças gradativas que são localmente produzidas, envolvendo novidades criadas por atores que necessitam ser nutridas em espaços protegidos para desenvolverem plenamente as suas potencialidades (ROEP; WISKERKE, 2004).

Moors et al. (2004) argumentam que, apesar de muitas vezes a necessidade de mudança do regime prevalente da agricultura estar suficientemente clara, os meios para examinar como tal mudança deveria ser realizada é pouco explorada. Muitos pesquisadores defendem que o conceito de produção de novidades, associado às noções de regime sociotécnico ${ }^{15}$ e espaços protegidos poderiam ajudar a encontrar alternativas de solução a crise multifacetada que a agricultura está agora vivenciando. Esses autores defendem que uma melhor compreensão das dinâmicas de inovação ${ }^{16}$ nas práticas agrícolas e, consequentemente, das mudanças de direção nos regimes existentes, podem ser alcançadas ao se lançar mão de uma abordagem multinível sobre processos de inovação, estudando, a relação entre "criação de novidades", sua nutrição e estímulo ou repressão, e a evolução do regime agrícola. Conforme Geels (2004), na perspectiva multinível, três níveis são distinguidos, os quais são conceitos heurísticos e analíticos para compreender as complexas dinâmicas de mudança sociotécnica. Com base em Geels (2004), os níveis são: paisagem, regime e nicho de inovação.

As trajetórias tecnológicas estão situadas em uma paisagem sociotécnica, consistindo de um grupo de profundas tendências estruturais. A paisagem sociotécnica contém um conjunto heterogêneo de fatores de "mudança-lenta", tais como, valores normativos e culturais, coalizões políticas amplas, desenvolvimentos econômicos de longo prazo, problemas ambientais cumulativos, processos demográficos e migratórios. O principal ponto é que a paisagem é um contexto externo para os atores nos espaços protegidos e regimes.

Um regime sociotécnico, por sua vez, incorpora uma estrutura normativa e cognitiva e um conjunto de relacionamentos funcionais entre os componentes tecnológicos e os atores ao longo da cadeia. Essa estrutura forma a base para a ação coletiva e individual, e fornece o contexto para as práticas econômicas e tecnológicas dentro da cadeia de um produto, predefinindo as atividades de solução de problemas dos engenheiros e as escolhas estratégicas das companhias (MOORS et al., 2004). Mais adiante, com base nesta definição, será configurado o regime sociotécnico prevalente na pecuária de corte.

No interior do regime sociotécnico dominante, a natureza da mudança sociotécnica é, na maioria das vezes, somente incremental ${ }^{17}$, pelo enraizamento de

\footnotetext{
${ }^{15} \mathrm{O}$ termo sociotécnico se refere à existência de um incrustamento de aspectos econômicos e tecnológicos em contextos sociológicos (percepções partilhadas, redes sociais, crenças profissionais, valores culturais). Assim, os contextos de transição envolvem ambientes dinâmicos em níveis sociais múltiplos (global, nacional, local, unidade produtiva, ambiente institucional). Envolvem também múltiplos atores e são fruto de processos co-evolucionários decorrentes da interação entre tecnologias, atores sociais, instituições e ambiente no transcurso de um período de tempo.

${ }^{16}$ Com base em Ventura e Milone (2004) inovação na agricultura pode ser descrita como um processo que torna possível realizar novas vantagens competitivas através de novas formas de produção, novos produtos ou novos métodos de organização. É um processo que "tem seu tempo" e toma lugar dentro de um ambiente específico no qual existem restrições e oportunidades pré-existentes (VENTURA; MILONE, 2004).

17 Inovação incremental se refere às melhorias contínuas em processos de produtos e tecnologias já existentes e estabelecidos (MARKARD; TRUFFER, 2008). É aquela que surge nos processos de pesquisa e desenvolvimento (P\&D) das empresas, os quais são engendrados em direção à melhoria de produtos existentes e na redução de seus custos de produção (KEMP; SCHOT; HOOGMA, 1998). Portanto, são
} 
tecnologias existentes em mais amplos sistemas, nas rotinas e práticas de produção, nos padrões de consumo, nos sistemas de crenças em administração e engenharia e em valores culturais. Neste contexto, as inovações dependem estritamente das inovações anteriores e, portanto, o processo tecnológico avança com base do conhecimento disponível, e sem romper com o path dependence embutido nestes padrões (VENTURA; MILONE, 2004).

A noção de 'nicho de inovação tecnológica' circunscreve o nível micro (ou local) da ação inovativa. Nele, o grau de institucionalização não é forte como no regime (GEELS, 2004), porém, há novas regras emergindo e o papel dos atores sociais e do conhecimento contextualizado localmente são proeminentes. Marques (2011) reforça que este é o lócus potencial para mudanças radicais na agricultura. É neste mesmo sentido que a ideia de 'espaço protegido' tem sido usada nos estudos sobre transições na agricultura. As evidências empíricas mostram que é neste espaço que surgem e evoluem as dinâmicas sociotécnicas locais e sustentáveis em processos distintos de desenvolvimento rural (PLOEG et al., 2004; STUIVER et al., 2004; VENTURA; MILONE, 2004; et al.,). As práticas sustentáveis, os processos de aprendizagem associados e a produção contínua de novidades, algumas promissoras, outras não, somente são possíveis pela gradual e persistente criação e manutenção de um espaço protegido (PLOEG et al., 2004).

$\mathrm{Na}$ ausência de proteção apropriada, muitas das novas atividades agrícolas e não agrícolas serão sufocadas devido à presença de barreiras normativas associadas com o regime dominante (VENTURA; MILONE, 2004). Para Paz e Dios (2011) os espaços protegidos se referem ao aparecimento de redes interinstitucionais público-privadas, capazes de impulsionar processos de desenvolvimento rural e de assegurar um fluxo de recursos econômicos provenientes do contexto, que estão orientados prioritariamente aos segmentos com maiores necessidades no território (agricultura familiar, povos tradicionais, etc.). Os segmentos vulneráveis, a partir da visão dominante capitalista/industrial/moderna são, recorrentemente, considerados 'resíduos' e 'anomalias' que tendencialmente desaparecerão no futuro.

Para Ploeg et al. (2004), Ploeg e Marsden (2008) e Ploeg (2011), um espaço protegido é configurado por um conjunto de atores sociais (entidades, organizações, empresas, poder público e agricultores), atividades, recursos, instituições, níveis e redes que, deliberadamente, se direcionam para priorizar segmentos específicos da sociedade a fim de que estes tenham chances de enfrentar autonomamente o interesse seletivo do capital e do mercado e os preconceitos do conhecimento científico hegemônico.

Uma das faces dessa dinâmica de valorização focaliza, invariavelmente, a coprodução $^{19}$ homem-natureza, baseada em sistemas de produção adaptados localmente, com forte carga histórica e cultural. Assim fazendo, se interessa também, e investe, em soluções tecnológicas, organizacionais, institucionais e

aquelas inovações que, por serem geradas no interior das estruturas do regime sociotécnico dominante, contribuem para o seu desenvolvimento e consolidação.

${ }^{18} \mathrm{Na}$ década de 1980, David (1985 apud Tomassini, 2011) investido em analisar os processos de desenvolvimento, de difusão e, principalmente, de adoção de tecnologias, percebeu que algumas inovações tecnológicas tornavam-se padrão de mercado mesmo estando longe de serem modelos ótimos (e.g. o padrão QWERTY de disposição das letras em um teclado). David (1985 apud Tomassini, 2011) identificou as causas deste fenômeno como sendo relacionadas aos retornos crescentes, economias de escala e uma consequente irreversibilidade. Em relação a essas razões o autor cunhou o termo path dependence, que evolui como consequência da história do próprio processo, evidenciando assim que a história interessa.

${ }_{19} \mathrm{Diz}$ respeito à interação e transformação mútua constante entre o homem e a natureza, num processo contínuo de configuração e reconfiguração de recursos sociais e naturais (PLOEG, 2008, p. 40). 
práticas que foram e são forjadas localmente em resposta às restrições de recursos, às especificidades ambientais e necessidades sociais.

Os espaços protegidos são importantes para os sistemas de inovação, por que eles fornecem locação para processos de aprendizagem e para enraizamento institucional. São importantes também por que fornecem espaço para dinâmicas de adaptação sobre o modo de fazer e conduzir as coisas; e para a construção de redes sociais ${ }^{20}$, as quais apóiam a inovação, assim influenciando o processo de transição geral (GEELS, 2004; MOORS et al., 2004).

Partindo da PMN, a dinâmica das transições sociotécnicas é compreendida como um processo interativo de mudança ao nível de espaços protegidos e ao nível de regime sociotécnico, ambos inseridos em uma paisagem exterior de fatores. Do ponto de vista evolucionário, um regime representa um ambiente já selecionado pelo desenvolvimento tecnológico em certo setor, que acaba exercendo uma significativa barreira para a difusão de novidades, ou inovações radicais ${ }^{21}$ (MARQUES, 2011). Desse modo, a probabilidade de surgimento de inovações realmente transformadoras é maior ao nível do espaço protegido. As transições começam por mudanças gradativas que são localmente produzidas.

\section{O REGIME SOCIOTÉCNICO PREVALENTE E O AVANÇO SOBRE O PAMPA}

Ainda que a questão da degradação do bioma Pampa seja de reconhecimento público e científico, o avanço sobre as áreas de campo tem sido intensificado. Em parte, tal avanço se deve a diferentes políticas e programas públicos e privados pretensamente estimuladores do desenvolvimento regional, resultando no alastramento de monocultivos (florestais e agrícolas) e na estruturação de regimes sociotécnicos na agricultura e na pecuária de corte, que foram se tornando dominantes.

Ressalta-se que o regime sociotécnico dominante da pecuária de corte no Brasil e no Rio Grande do Sul se caracteriza pela presença de: grandes conglomerados industriais de produção de insumos e de abate e processamento da carne; grandes conglomerados atacadistas e varejistas de distribuição de produtos acabados; extensas áreas de monocultivo agrícola e pastoril com emprego massivo de insumos químicos industrializados, de máquinas e implementos complexos; intensos projetos de confinamento de bovinos com alimentação baseada em concentrados; um conjunto de normas legais para a funcionalidade do regime; além das relações entre grupos de interesse e os três poderes do Estado, engendradas para a criação, aprovação e cumprimento de tais regras; atividades agropecuárias direcionadas primordialmente para o lucro capitalista; investimento prioritário, público e privado, em pesquisas científicas sobre engenharia genética e novos princípios ativos químicos para uso veterinário e agrícola; grandes feiras agropecuárias para

20 Marques, Dal Soglio, Ploeg (2010 e 2012) argumentam que a fim de responder metodológica e analiticamente ao nível das relações sociais que ocorrem no espaço protegido é necessário lançar mão de abordagens integrativas e interdisciplinares. Neste sentido, tanto a perspectiva multinível como a da ação social - Perspectiva Orientada ao Ator (LONG, 2001; LONG; PLOEG, 2011) partem de uma compreensão multidimensional de 'agência', assumindo que os atores têm seus próprios interesses e agem estrategicamente, embora limitados por uma ampla estruturação. A agência humana atribui ao ator (individual ou grupo social) a capacidade de processar experiências sociais e inventar caminhos para responder a situações problemáticas. Agência é composta por relações sociais e pode somente tornar-se efetiva através delas, então ela requer capacidade de organização (LONG; PLOEG, 2011).

${ }^{21} \mathrm{~A}$ inovação radical se refere às mudanças que são prováveis de acontecer através de uma história única e complexa de eventos inter-relacionados, que pressionam o rompimento da estabilidade do regime, mudando a sua configuração consolidada de instituições, técnicas e artefatos, bem como de regras, práticas e redes que determinam o seu desenvolvimento "normal" e o uso de tecnologias (SMITH et al., 2005). 
comercialização e exposição de máquinas e genética animal considerada "de ponta"; e logística e infraestrutura para atendimento do mercado global a grandes distâncias, via portos, aeroportos e rodovias. Cabe salientar, ainda, que o regime sociotécnico prevalente se consolida através de atributos cognitivos, culturais e sociais arraigados na mente das pessoas, desde fazedores de política, passando pelos cientistas e técnicos (e suas heurísticas), até os consumidores finais (impactados pelo marketing balizado por um convencimento das vantagens higiênico-sanitárias dos processos de industrialização da carne).

0 processo de modernização da agricultura ${ }^{22}$ desempenhou um papel preponderante na consolidação do regime dominante na agricultura. Essa onda transformadora, a partir da $2^{\mathrm{a}}$ Guerra Mundial, apesar de impactos desiguais para as regiões, para segmentos de produtores e para setores da economia e sociedade, apresentou reflexos significativos na agricultura nacional. Em diferentes momentos deste processo, com maior ou menor intervenção Estatal ${ }^{23}$, as ações foram majoritariamente articuladas no sentido de tornar a agricultura capitalista viável, com investimentos em infraestrutura de transporte e armazenamento, industrialização dos insumos, tecnificação dos sistemas de produção, e complexas conexões da produção primária para transformação das matérias-primas e para comercialização dos produtos finais.

A consolidação da atividade pecuária empresarial no RS, nada mais é que um processo de elevação da base técnica produtiva, no bojo do processo de modernização. Entretanto, apesar dos evidentes resultados nas dimensões, econômica e técnico-produtiva, esse processo de tecnificação progressiva, também intensifica o que Santos (1992) denomina de ruptura entre homem e o seu entorno ${ }^{24}$. Adicionalmente, essa agricultura construída como convencional, inserida profundamente no paradigma técnico-científico moderno ${ }^{25}$, frustra crescentemente os interesses e perspectivas daqueles diretamente envolvidos nela (e.g. por perda sistemática de renda e problemas de saúde vinculados ao uso de agrotóxicos); e provoca a reflexão desconfiada da sociedade em geral com a qualidade e quantidade dos alimentos. É o retrato cristalino de uma crise, que se expressa nas dimensões, ambiente, sociedade e atores envolvidos, e por causa dela, ganha corpo uma corrente de mobilização e resistência (ESCOBAR, 2002; PLOEG et al., 2004; PLOEG, 2008; WISKERKE, 2010).

Nesse processo controvertido, com consequências positivas e negativas, a "modernização" segue seu caminho e provoca redefinições importantes nos ciclos de produção da pecuária, nas relações sociais e na racionalidade dos negócios. Contudo, mesmo nos dias de hoje, persiste o paradoxo da existência contemporânea do conjunto de pecuaristas que têm a capacidade local para reproduzir e ampliar o modelo "modernizante", e o robusto conjunto dos pecuaristas, ditos "tradicionais", aqueles "incapazes", total ou parcialmente, de adotar e aprofundar a implantação dos pacotes de elevação da base técnica moderna, e de inserção nas grandes cadeias de industrialização e comercialização do mercado capitalista.

\footnotetext{
${ }^{22}$ Para mais detalhes consultar: Navarro (2001); Buarque (2002); Delgado (2009).

${ }^{23}$ Para mais detalhes sobre o neoliberalismo e seus reflexos na agricultura consultar: Leite (2009); Belik e Paulillo (2009).

${ }^{24}$ Para Santos (1992), quando o homem aprofunda a trajetória de mecanização, armando-se de novos instrumentos para dominação da natureza, cria-se um novo modelo de vida, do qual advêm os problemas de relacionamento entre a civilização atual material e a natureza.

${ }^{25}$ As hipóteses aceitas como normas nesse modelo são do tipo: "Boa agricultura é agricultura de produtividade", ou "Boa agricultura é dirigida por tecnologia e orientada pelo mercado" (STUIVER et al. 2004).
} 


\section{DA PERSISTÊNCIA DA EXPLORAÇÃO "TRADICIONAL" À INOVAÇÃO NA PECUÁRIA DE CORTE NO RIO GRANDE DO SUL}

Voltando-se o olhar para os supostos "incapazes", é importante destacar pesquisas (SENAR, 2005; MIGUEL et al., 2007) ${ }^{26}$ que indicam que a realidade gaúcha não difere do cenário nacional, com significativa parcela dos rebanhos sendo manejada com pouco investimento e com base em recursos internos, a despeito de outra parcela que investe intensamente em tecnologias modernas de produção, fortemente conectadas às cadeias industriais à montante e à jusante da produção pecuária primária. Apesar da nítida presença de um regime sociotécnico prevalente na pecuária de corte, com um conjunto de crenças, artefatos e tecnologias fortemente consolidado, a maioria dos produtores adere, parcialmente, e de maneira distinta, a estes padrões de modernização.

A persistência destes pecuaristas familiares gaúchos engrossa o "contra movimento' da resistência camponesa, ou, dito de outra forma, o processo transicional do desenvolvimento rural, que flui através da multiplicidade de respostas (trajetórias) que são ativamente criadas para enfrentar e contrapor a desestruturação dos mercados; a drenagem de valor agregado; a perda de autonomia; a invisibilidade imposta aos produtores pelas grandes cadeias agroalimentares de industrialização e distribuição; e a capitalização desenfreada do mercado, processo no qual tudo (força de trabalho, conhecimento, produtos, serviços) é convertido em mercadoria (PLOEG, 2008).

Muitos estudos e pesquisadores têm tratado essas trajetórias de resistência e de mobilização como movimentos de transição ou dinâmicas sociotécnicas na agricultura $^{27}$, nas quais, as condições ecológicas e fatores de produção disponíveis localmente tem sido o ponto de partida do desenvolvimento rural contemporâneo para alcançar equilíbrios sustentáveis (STUIVER et al., 2004; VENTURA; MILONE, 2004).

No início de uma caminhada de distanciamento das regras e ordenamentos do regime dominante, os agricultores estão ingressando em um território ainda desconhecido e carente de apoio, mas gerando novidades, às vezes, inconscientemente, para levar adiante a rotina das atividades e para superação de obstáculos. Em função disso, Ventura e Milone (2004) recomendam que seja proveitoso e imprescindível criar um espaço protegido ao redor deles que torna possível a escalada, além da dimensão na qual as novidades estão geralmente confinadas. A exclusão/afastamento de propriedades ou grupo de propriedades do processo inovativo incremental intrínseco ao regime sociotécnico dominante tem levado a criação de espaços protegidos para as novidades. Esses espaços criam o ambiente no qual a chance de sobrevivência para essas propriedades, as quais eram anteriormente consideradas como marginais, é fortalecida (VENTURA; MILONE, 2004).

Inúmeras comunidades de pecuaristas familiares nos campos gaúchos, através de processos co-evolutivos entre humanos e condições ambientais locais, estabelecem práticas e trajetórias criativas que (re) configuram recursos, atividades,

\footnotetext{
${ }^{26}$ A bovinocultura de corte está presente em todas as regiões agroecológicas do estado e compõe 16 (dezesseis) sistemas de produção com as mais diversas formatações e os diferentes sistemas de produção são condicionados por fatores de ordem cultural, ecológica (meio físico - solo, topografia, clima), ou mesmo conjunturais (preços e mercados). Mais detalhes em SENAR (2005) e Miguel et al. (2007).

${ }^{27}$ Por exemplo, os trabalhos publicados em Wiskerke e Ploeg (2004), Ploeg e Marsden (2008), bem como teses e dissertações desenvolvidas no Programa de Pós-Graduação em Desenvolvimento RuralPGDR/UFRGS. Para mais detalhes consultar Nicola (2015).
} 
transações e redes. Para que este movimento se consolide e evolua, intensificando um processo transicional em direção ao uso sustentável e conservação dos campos sulinos, é necessário um conjunto amplo e interconectado de apoios institucionais, organizacionais, tecnológicos, financeiros, políticos e mercadológicos. No caso gaúcho, essas dinâmicas de desenvolvimento rural podem ser observadas em experiências levadas adiante no Território Alto Camaquã, no Projeto RS Biodiversidade e na Região Centro Sul do Estado. O Projeto RS Biodiversidade apresenta alguns objetivos específicos voltados ao rearranjo contextualizado dos sistemas produtivos visando a conservação ambiental (RS BIODIVERSIDADE, 2013). Apesar das especificidades de cada caso, as trajetórias do Território Alto Camaquã (BORBA et al., 2009) e da região Centro Sul (NICOLA, 2015) apresentam práticas criativas em governabilidade de novos mercados e estabelecimento de redes de atores para alavancar um tipo de desenvolvimento que se apoia e valoriza as peculiaridades dos pecuaristas familiares e as condicionantes locais. Na região Centro Sul os atores sociais se articularam para conceber novas formas de fazer a comercialização de animais via feiras e remates adaptados às especificidades dos pecuaristas familiares, e tem dispensado grandes esforços para iniciar o comércio regional da carne de cordeiro com marca coletiva, através do arranjo institucional da Associação Regional de Ovinocultores (NICOLA, 2015). O Território Alto Camaquã já conta com uma marca coletiva para a carne de cordeiro e outros produtos regionais.

Essas evidências empíricas em solo rio-grandense fortalecem a ideia de que a construção de mercados é um dos apoios importantes a serem empenhados no trabalho com este segmento. Mas esses mercados precisam ser reconfigurados e governados de uma maneira distinta e original daquela que orienta as relações no interior das redes verticais (MIOR, 2006). Precisa ser diferente, para que se obtenham ganhos em autonomia dos agricultores e em valor agregado para os produtos (PLOEG; MARSDEN, 2008).

Outra mudança necessária refere-se à abordagem ao segmento social dos pecuaristas familiares e à relação estabelecida entre agricultores, extensionistas e cientistas, visando a superação do "modelo linear de inovação" 28. Em vista da melhor compreensão sobre como as inovações bem sucedidas acontecem na prática, e o reconhecimento de que o "modelo linear", na verdade, está sujeito a uma série de desvios, é cada vez mais aceita a ideia de que uma inovação exige uma estreita cooperação em uma rede de atores, na qual todos contribuem para a geração, para a transferência, e aplicação (STUIVER et al., 2004). Desse modo, os agricultores passam a ser considerados como detentores de conhecimentos valiosos, enraizados localmente, e sendo capazes de desempenhar um papel ativo no processo. Um processo de inovação requer, então, a construção de redes, aprendizado coletivo, o estabelecimento de coalizões e negociações a fim de chegar a novos modos de ação coordenada (STUIVER et al., 2004).

Neske et al. (2014), neste sentido, identificam que o conhecimento e a valorização da experiência acumulada pelos pecuaristas familiares no Território Alto Camaquã foram o ponto de partida para a construção de novidades no território, sendo o ambiente organizacional favorável nas empresas de pesquisa e extensão

\footnotetext{
${ }^{28} \mathrm{Na}$ tradição de pesquisa de "adoção e difusão de inovação" a percepção básica era de que as inovações se originavam a partir dos cientistas, eram transferidas por agentes de extensão ou outros intermediários e depois eram aplicadas pelos produtores rurais. Esse modo de enxergar o processo de fluxo do conhecimento, entre a ciência e a prática, é denominado de "modelo linear de inovação" e é caracterizado por uma clara divisão de tarefas entre os vários atores, aqueles que geram a inovação, aqueles que transferem, e os agricultores, com o singelo papel de colocar em prática o que foi gerado (STUIVER et al., 2004).
} 
rural um importante primeiro passo. Neste sentido, o próprio arranjo inovador entre as organizações, uma vez construído contra os regramentos dominantes do regime modernizador, significa uma novidade (NESKE et al., 2014).

O rompimento da linearidade no processo de inovação, assim como a efetiva valorização dos conhecimentos autóctones, requer planejar, executar e avaliar as práticas e seus impactos de uma forma que valorize as especificidades locais, inclusive ambientais e culturais, considerando que mesmo os segmentos considerados mais vulneráveis no conjunto da sociedade desenvolvem conhecimentos e estratégias de ação que são relevantes para os processos de transição e mudança. Essa compreensão se fortalece como uma resposta àquele tipo de agricultura que se organiza e se desenvolve globalmente, trazendo consigo a destruição sistemática dos ecossistemas e a contaminação cada vez maior do ambiente.

\section{CONSIDERAÇÕES FINAIS}

O argumento elaborado, ao longo do texto, advoga que a transição em direção a sistemas produtivos que garantam a perpetuação da multifuncionalidade das áreas campestres (e os próprios campos em sua diversidade biológica) passa pelo estabelecimento de espaços que protejam comunidades e regiões de pecuaristas familiares, valorizem a coprodução homem-natureza, testem e reconfigurem recursos nativos locais para a promoção do bem estar socioeconômico e preservação ambiental.

Por outro lado, os procedimentos técnico-científicos e as crenças a eles associadas têm seu poder fortemente construído pelo regime sociotécnico prevalente. E, neste sentido, quando atores sociais ou articulações dos mesmos decidem estabelecer novas 'regras', abandonando ou 'desviando-se' da aparente inevitabilidade da modernização ou da exclusão, emergem 'espaços protegidos'. Neles, são criadas condições para as novidades, aquelas que podem ser associadas aos contra movimentos, que rompem hegemonias e descortinam potencialidades.

Porém, muitas dessas iniciativas, em seu início, poderão fracassar, pois se defrontarão com forças desiguais emanadas dos padrões dominantes de produção, comercialização, abastecimento e consumo. Assim, diante deste cenário de transformações e mudanças, muitos estudiosos do desenvolvimento rural buscam respostas a respeito dos fatores, das relações e das atividades que levam uma área a se desenvolver de maneira diferente que outra, mesmo que estejam inseridas em contextos macro aparentemente homogêneos (PLOEG, 2011).

Numa visão geral, pode-se afirmar que parcela significativa dos pecuaristas familiares pratica aquela pecuária considerada "tradicional", com algumas ações de manejo que remetem ao que era usual em sistemas de produção do século XIX. Partindo de certos pontos de vista, estes têm futuro pouco promissor e tendem ao desaparecimento, na medida em que os produtos finais da atividade não atendem aos padrões exigidos pelo mercado global da carne. Entretanto, partindo do ponto de vista da conservação e uso sustentável do recurso forrageiro nativo e valorização cultural, diversas pesquisas e experiências recentes têm salientado a relevância do pecuarista familiar para o desenvolvimento rural sobre as áreas campestres do RS, recomendando o fortalecimento e garantia de futuro para este segmento social.

Os atores locais de algumas regiões dos campos sulinos gaúchos têm levado adiante ações de desenvolvimento e promoção da pecuária familiar. Tais ações podem ser vistas como repletas de singularidades criativas que trazem significativos resultados em manejo e melhoramento do campo nativo; manejo e melhoramento dos rebanhos; organização social dos pecuaristas; apoio à 
comercialização; e estabelecimento e manutenção de redes com abrangência local e regional.

A criação de condições sócio institucionais para a constituição de espaços protegidos para consolidação da pecuária familiar e conservação dos campos sulinos depende de uma dinâmica de desenvolvimento que atenda os requerimentos contemporâneos da sustentabilidade. Além disso, as políticas públicas devem ser efetivas e contínuas no reconhecimento da multiplicidade de atores sociais envolvidos nesse processo contextualizado, valorizando e incorporando as diversidades ecológicas, econômicas, sociais e culturais presentes no rural.

\section{REFERÊNCIAS}

BELIK, W.; PAULILLO, L. F. O financiamento da produção agrícola brasileira na década de 90: ajustamento e seletividade. In: LEITE, S. P. (Org.) Políticas públicas e agricultura no Brasil, 2. ed. Porto Alegre: Editora da UFRGS, 2009. 256 p. (Série Estudos Rurais).

BENCKE, G. A. Diversidade e conservação da fauna dos Campos do Sul do Brasil. In: PILLAR, V. P.; MÜLLER, S. C.; CASTILHOS, Z. M. S.; JACQUES, A. V. Á. (Ed.). Campos Sulinos: conservação e uso sustentável da biodiversidade. Brasília: MMA, 2009.p. 101-121.

BORBA, M. F. S. et al. Ecologização da pecuária na Serra do Sudeste. Bagé: Embrapa Pecuária Sul, 2009. (Documentos/Embrapa Pecuária Sul, 98). 69 p. Disponível em: <http://www.cppsul.embrapa.br/unidade/publicacoes:list/231> Acesso em: 22 abril 2012.

BORBA, M.; TRINDADE, J. P. P. Desafios para conservação e a valorização da pecuária sustentável. In: PILLAR, V. P.; MÜLLER, S. C.; CASTILHOS, Z. M. S.; JACQUES, A. V. Á. (Ed.). Campos Sulinos: conservação e uso sustentável da biodiversidade. Brasília: MMA, 2009. p. 391-403.

BUARQUE, S. C. Construindo o desenvolvimento local sustentável. Metodologia de Planejamento. Rio de Janeiro: Garamond, 2002. 180 p.

CARNEIRO, M. J. Multifuncionalidade da agricultura e ruralidade: uma abordagem comparativa. Porto Alegre: CPDA/UFRRJ, 2002. (Textos para Discussão).

CARNEIRO, M. J. Pluriatividade da agricultura no Brasil: uma reflexão crítica. In: SCHNEIDER, S. A diversidade da agricultura familiar. Porto Alegre: Editora da UFRGS, 2006. 296 p. (Série Estudos Rurais).

CARVAlHO, P. C. F. et al. Produção Animal no Bioma Campos Sulinos. Brazilian Journal of Animal Science, v. 35, suplemento especial, p. 156-202, 2006.

DELGADO, N. G. Política econômica, ajuste externo e agricultura. In: LEITE, S. P. (Org.) Políticas públicas e agricultura no Brasil, 2. ed. Porto Alegre: Editora da UFRGS, 2009. 256 p. (Série Estudos Rurais). 
DONAZZOLO, J; BALEM, T. A.; SILVEIRA, P. R. C. Conhecimento tradicional: base para o desenho de sistemas agroflorestais. Extensão Rural, v. 19, n. 2, p. 29-54, 2012.

ELLIS, F.; BIGGS, S. Evolving themes in rural development 1950s - 2000s. Development policy review. Oxford: Blackwell Publishers, 2001.

ESCOBAR, A. Globalización, desarollo y modernidad. In: CORPORACIÓN REGIÓN. Planeación, Participación y Desarrollo. Medellín: Corporación Región, 2002. p. 9 32. Disponível em: <http://www.oei.es/salactsi/escobar.htm>. Acesso em: 26 março 2012.

GEELS, F. W. Understanding system of innovation: a critical literature review and a conceptual synthesis. In: ELZEN, B.; GEELS, F. W.; GREEN, K. System innovation and the transition to sustainability: theory, evidence and policy. Cheltenham: Northampton: Edward Elgar, 2004. p. 19-47.

INSTITUTO BRASILEIRO DE GEOGRAFIA E ESTATÍSTICA-IBGE. Mapa de biomas do Brasil e mapa de vegetação do Brasil. Rio de Janeiro, IBGE, 2004. Disponível em: <http://www.ibge.gov.br>. Acesso em: 20 junho 2012.

KEMP, R.; SCHOT, J.; HOOGMA, R. Regime shifts to sustainability through processes of niche formation: the approach of Strategic Niche Management. Technology Analisys \& Strategic Management, v. 10, n. 2. p. 175-196, 1998.

LEITE, S. Apresentação. In: LEITE, S. P. (Org.) Políticas públicas e agricultura no Brasil, 2. ed. Porto Alegre: Editora da UFRGS, 2009. 256 p. (Série Estudos Rurais).

LONG, N. Development sociology: actor perspectives. London: Routledge 2001.

LONG, N.; PLOEG, J. D. van der. Heterogeneidade, ator e estrutura: para a reconstituição do conceito de estrutura. In: SCHNEIDER, S.; GAZZOLA, M. Os atores do desenvolvimento rural: perspectivas teóricas e práticas sociais. Porto Alegre: Editora da UFRGS, 2011.328 p.

MARKARD, J.; TRUFFER, B. Technological innovation systems and the multi-level perspective: towards an integrated framework. Research Policy, n. 33, p. 596-615, 2008.

MARQUES, F. C.; DAL SOGLIO, F. K.; PLOEG, J. D. van der. Construing Sociotechnical Transitions toward Sustainable Agriculture: lessons from ecological production of medicinal plants in southern brazil. In: Innovation and sustainable development in agriculture and food-international symposium, 2010. Montpellier: Cirad-Inra-SupAgro, 2010.

MARQUES, F. C. Nicho e novidade: nuanças de uma possível radicalização inovadora na agricultura. In: SCHNEIDER, S.; GAZZOLA, M. Os atores do desenvolvimento rural: perspectivas teóricas e práticas sociais. Porto Alegre: Editora da UFRGS, 2011. $328 \mathrm{p}$.

MARQUES, F. C.; PLOEG, J. D. van der; DAL SOGLIO, F. K.; New Identities, new commitments: something is lacking between niche and regime. In: ELZEN, B.; 
BARBIER, M. (Org.). System innovations, knowledge regimes, and design practices towards sustainable agriculture, 1. ed. Tolouse: INRA, 2012. p. 23-46.

MIGUEL, L. A. et al. Caracterização socioeconômica e produtiva da bovinocultura de corte no estado do Rio Grande do Sul. Estudos e Debates, v. 14, n. 2. p. 95-125, 2007.

MIOR, L. C. Desenvolvimento rural: a contribuição da abordagem das redes sociais e sociotécnicas. In: SCHNEIDER, S. (Org.) A Diversidade da Agricultura Familiar. Porto Alegre: Editora da UFRGS, 2006. 295 p. (Série Estudos Rurais).

MOORS, E.; RIP, A.; WISKERKE, J. S. C. The dynamics of innovation: a multi-level co-evolutionary perspective. In: WISKERKE, J.S.C.; PLOEG, J.D. van der. Seeds of Transitions. Assen: Royal Van Gorcum, 2004. p. 31-56.

NABINGER, C.; CARVALHO, P. C. F.; DALL'AGNOL, M. Pastagens no ecossistema de clima subtropical. In: 42a Reunião Anual da Sociedade Brasileira de Zootecnia, 2005, Goiânia. Anais.... Goiânia: SBZ, 2005. v. 1. p. 1-20.

NABINGER, C.; CARVALHO, P. C. F. Avanços no manejo do pasto para a produção bovina. In: III Jornada Técnica em sistemas de produção de bovinos de corte e cadeia produtiva: a pecuária que dá certo, 2008, Porto Alegre. Anais...Porto Alegre: NESPRO/UFRGS, 2008. p. 21-70.

NABINGER, C. et al. Produção animal com base no campo nativo: aplicações de resultados de pesquisa. In: PILLAR, V. P.; MÜLLER, S. C.; CASTILHOS, Z. M. S.; JACQUES, A. V. A. (Ed.). Campos Sulinos - conservação e uso sustentável da biodiversidade. Brasília: MMA, 2009. p. 175-198.

NAVARRO, Z. Desenvolvimento Rural no Brasil: os limites do passado e os caminhos do futuro. Estudos Avançados: dossiê desenvolvimento rural. São Paulo, v. 15 n. 43. p. $83-100,2001$.

NESKE, M. Z. et al. A emergência da produção de novidades em territórios "marginalizados": uma análise a partir do território Alto Camaquã, Rio Grande do Sul. Desenvolvimento e Meio Ambiente. Curitiba, v. 31. p. 43-57, 2014.

NICOLA. M. P. Espaço Protegido e Desenvolvimento Rural: práticas e trajetórias na pecuária familiar da região Centro Sul do Rio Grande do Sul, 2015. 239 f. Tese (Doutorado em Desenvolvimento Rural) - Faculdade de Ciências Econômicas. Universidade Federal do Rio Grande do Sul, Porto Alegre, 2015.

PAZ, R. G.; DIOS, R. E. Actores sociales y espacios protegidos. Tucumán: Magna Publicaciones, 2011. 200 p.

PILLAR, V. P.; MÜLLER, S. C.; CASTILHOS, Z. M. S.; JACQUES, A. V. Á. (Ed.). Campos Sulinos - conservação e uso sustentável da biodiversidade. Brasília: MMA, 2009. 403 p.

PLOEG, J. D. van der. et al. Rural Development: from Practices and Policies towards Theory. Sociologia Ruralis. Wageningen, v. 40, n. 4, 2000. p. 391-408. 
PLOEG, J. D. van der; et al. On regimes, novelties and co-production. In: WISKERKE, Johannes S.C.; PLOEG, J.D. van der. Seeds of Transitions. Assen: Royal Van Gorcum, 2004. p. 1 - 30.

PLOEG, J. D. van der; MARSDEN, T. Unfolding Webs: The Dynamics of Regional Rural Development. Amsterdam: Royal Van Gorcum, 2008.

PLOEG, J. D. van der. Camponeses e Impérios Alimentares: lutas por autonomia e sustentabilidade na era da globalização. Porto Alegre: UFRGS, 2008.

PLOEG, J. D. van der. Introducción. In: PAZ, R.G.; DIOS, R. E. Actores sociales y espacios protegidos. Tucumán: Magna Publicaciones, 2011. $200 \mathrm{p}$.

PLOEG, J. D. van der. Peasants and the art of farming: a chayanovian manifesto. Halifax. FS: Fernwood, 2013. 157 p.

RAY, C. Towards a meta-framework of endogenous development: repertoires, paths, democracy and rights. Sociologia Ruralis. Wageningen, v. 39, n. 4, p. 521-537, 1999.

RIBEIRO, C. M. Pecuária familiar na Região da Campanha do Rio Grande do Sul. Série Realidade Rural. v. 34. p. 11 - 45. Porto Alegre: EMATER/RS-ASCAR, 2003.

RIBEIRO, C. M. Estudo dos modos de vida dos pecuaristas familiares da região da Campanha do Rio Grande do Sul. 2009. 303 f. Tese (Doutorado em Desenvolvimento Rural) - Faculdade de Ciências Econômicas. Universidade Federal do Rio Grande do Sul, Porto Alegre, 2009.

RIO GRANDE DO SUL.Decreto no 48.316. Regulamentação do Programa Estadual de Desenvolvimento da Pecuária de Corte Familiar. Diário Oficial do Estado do Rio Grande do Sul, Porto Alegre, 01 setembro 2011.

ROEP, D.; WISKERKE, J. S. C. Reflecting on Novelty Production and Niche Management. In: WISKERKE, J. S. C.; PLOEG, J. D. van der. Seeds of Transitons. Assen: Royal Van Gorcum, 2004. p. 341-356.

RS BIOBIODIVERSIDADE. Projeto RS Biodiversidade. Justificativa e Objetivos. Disponível em: <http://www.biodiversidade.rs.gov.br>. Acesso em: 19 abril 2013.

SABOURIN, E. Camponeses do Brasil: entre a troca mercantil e a reciprocidade. Rio de Janeiro: Garamond, 2009. 400 p.

SANTOS, M. 1992: a redescoberta da natureza. Estudos Avançados. São Paulo. v. 06. n. 14. p. $95-106,1992$.

SARDAN, J-P. O. Popular knowledge and scientific and technical knowledge. In: SARDAN, J-P. O. Anthropology and Development: Understanding Contemporary Social Change. London: Zed Books, 2005. p. 135-165.

SCHNEIDER, S. Situando o desenvolvimento rural no Brasil: o contexto e as questões em debate. Revista de Economia Politica. São Paulo, v. 30. n 3. p. 511$531,2010$. 
SENAR/RS; SEBRAE/RS; FARSUL.Diagnóstico de Sistemas de Produção de Bovinocultura de Corte do Estado do Rio Grande do Sul.2005. Relatório de Pesquisa - Centro de Estudos e Pesquisas Econômicas/IEPE. Universidade Federal do Rio Grande do Sul. Porto Alegre, 2005.

GUZMÁN, E. S. Origem, evolução e perspectivas do desenvolvimento sustentável. In: ALMEIDA, J.; NAVARRO, Z. Reconstruindo a agricultura: ideias e ideais na perspectiva do desenvolvimento sustentável. 3 ed. Porto Alegre: Editora da UFRGS, 2009.

SMITH, A.; STIRLING, A.; BERKHOUT, F. The governance of sustainable sociotechnical transitions. Research Policy, v. 34, p. 1491-1510. 2005.

STUIVER, M. et al. The Power of Experience: Farmers' Knowledge and Sustainable Innovations in Agriculture. In: WISKERKE, J.S.C.; PLOEG, J.D. van der. Seeds of Transitions. Assen: Royal Van Gorcum, 2004. p. 93-118.

TOMASSINI, R. A. S. A história interessa - path dependence e a indústria calçadista. 2011. 159 f. Dissertação (Mestrado em Administração) - Pontifícia Universidade Católica do Rio de Janeiro, Rio de Janeiro, 2011.

VALLS, J. F. M.; et al. O patrimônio florístico dos campos: potencialidades de uso e a conservação de seus recursos genéticos. In: PILLAR, V. P.; MÜLLER, S. C.; CASTILHOS, Z. M. S.; JACQUES, A. V. Á. (Ed.). Campos Sulinos: conservação e uso sustentável da biodiversidade. Brasília: MMA, 2009. p. 139-154.

VENTURA, F.; MILONE, P. Novelty as Redefinition of Farm Boundaries. In: WISKERKE, J. S. C.; PLOEG, J. D. van der. Seeds of Transitions. Assen: Royal Van Gorcum, 2004. p. 57- 89.

WANDERLEY, M. de N. B. Raízes históricas do campesinato brasileiro. In: ENCONTRO ANUAL DA ANPOCS, 20, 1996. Anais... Caxambu (MG), 1996.

WISKERKE, J. S. C.; PLOEG, J. D. van der. Seeds of Transitions. Assen: Royal Van Gorcum, 2004.

WISKERKE, J. S. C. On places lost and places regained: reflections on the alternative food geography and sustainable regional development. International Planning Studies. Cardiff, 2010. 